\title{
Mapping Aesthetic Development and Epistemological Understanding
}

\author{
Jeanne Klein
}

"We see things not as they are but as we are."

-Anaïs Nin

How do we know? What personal theories of mind do we hold about knowledge and knowing in general and theatre in particular? When critiquing performances, what sources of artistic knowledge, evidence, and criteria do we rely upon to articulate our aesthetic experiences and justify our judgments? If one goal of theatre education is to acquire and extend knowledge about human experiences, knowing how students and we ourselves think about that knowledge may assist us when teaching performance criticism.

Since the late 1960s, cognitive psychologists have examined how we acquire, understand, and construct knowledge as subjective knowers in relation to the objectively known world of phenomenal reality. Over time, we construct tacit theories about our minds as individual ways of knowing, known as a "personal epistemology," along four main dimensions. These dimensions include our perspectives regarding 1) the un/certainty of knowledge, 2) the simplicity and complexity of knowledge, 3 ) our sources of knowledge and evidence, and, 4) our assertions, claims, or justifications based on the criteria we employ to test the validity of our evidence. Convergent frameworks of personal epistemology are characterized by how often we position ourselves in four basic stances as 1) imitative realists, 2) dualistic absolutists, 3 ) relativistic multiplists, and 4) critical evaluatists. These domain-general perspectives or "stages" of epistemological understanding may operate in a spiraling progression of recursion in that we may repeat some traits from a previous stage in varying degrees depending on domain-specific tasks in situated contexts. ${ }^{2}$

In the specific domain of visual art, Michael Parsons has proposed a developmental framework of aesthetic epistemology that describes how we move

\footnotetext{
Jeanne Klein is an Associate Professor of Theatre at the University of Kansas where she teaches courses in theatre for young audiences, children and media, and drama with children. Her reception studies with child audiences and other articles have been published in the Youth Theatre Journal, Journal of Aesthetic Education, Canadian Children's Literature, and Theatre Research in Canada. An earlier version of this essay was presented for the Cognitive Studies working group at the 2008 ASTR conference, Boston.
} 
through stages or "sets of ideas" when discussing artworks' subject matter, artists" expressions, the forms and styles of visual media, and our judgments about each of these concepts. Like epistemologists, he marks the boundary of each stage by cognitive shifts in: 1) our primary mode of inquiry (i.e., perception, interpretation, and evaluation), 2) our expectations about the purposes of art, 3) our primary sources of artistic knowledge, and, 4) our primary criteria for making evaluative claims. Numerous studies in the visual arts have supported his framework with various populations, yet to date no one has offered an analogous epistemological framework for the domain of theatre. ${ }^{3}$

In this paper, I map Parsons's stages of aesthetic development onto Deanna Kuhn's "steps toward mature epistemological understanding" in order to propose a model of theatre epistemology regarding the contexts of performance criticism. This model offers a means or "coding" method of analyzing spectators' critical responses to performances to explain how and why they perceive, interpret, and evaluate theatrical events. While substantial evidence supports the existence of both personal theories of epistemological knowledge and aesthetic ways of knowing and judging visual artworks, we have no reception studies with novice and expert spectators that document how these four epistemological frameworks might function in combination when critiquing theatrical events. Therefore, it remains for future reception studies to provide reliable and credible evidence that supports or disproves the operative functions of these four stances in whole or in part. ${ }^{4}$

For example, Introduction to Theatre courses could provide productive sites for creating a body of reception studies with novice spectators. Within these contexts, instructors could pose specific questions to students regarding their epistemological stances when asking them to attend performances and write critical essays. They might begin by asking students: What are the purposes of theatre? How do you know? What criterial evidence do you use or rely upon to judge the artistic effectiveness of performances? Why? Professors could then analyze students' essays and categorize or code their responses according to the respective definitions of each epistemological stance. ${ }^{5}$ Over the course of a semester, they could then trace the development or progress students make to see whether and how students' evaluations of performances alter or change as a consequence of guided instruction in writing performance criticism. In other words, this formative method of reception research would serve as a "measurement" tool of student learning in performance criticism. Therefore, until we have an accumulated body of such reception evidence, I will suggest further questions professors might ask of their students, while offering anecdotal examples of each epistemological stance and its possible function in university contexts.

Before describing the characteristics of each epistemological position, it's important to foreground the assumptions underlying the "final end-state" of critical argumentation. Like other disciplines, educators in the arts and humanities value 
and privilege critical thinking - that is, the ability to evaluate and reflect upon one's personal beliefs, to argue for and justify one's assertions, and to question one's ideological claims based on myriad forms of criterial evidence. This overarching educational goal requires that students learn how to coordinate and integrate theories and evidence and to synthesize their subjective and objective modes of inquiry using both inductive and deductive reasoning. ${ }^{6}$ When teaching performance criticism, this means encouraging students to apply appropriate methodological theories and situate the evidence of performances in their historical and contemporary contexts. ${ }^{7}$ The following descriptions capture, in brief, the predominate characteristics of each epistemological stage toward these ends.

\section{Stage Position One: Realists' Preferences}

From stage one positions, realist spectators believe they may know a performance directly and with certainty simply by seeing and hearing the spectacle of its visual and aural imagery. Knowing what they like and dislike, they focus intuitively on their favorite aspects of the production and use inductive reasoning to associate artistic elements and decide whether particular externalized aspects meet with their general aesthetic preferences. Emotional experiences with this one "mere exposure" satisfy the need to make simple, all-or-none affective decisions about a performance's artistic qualities. With one sensory exposure to a performance, neuronal connections are activated in the pleasure areas of our brains so quickly that our feelings "tell" us immediately whether we prefer it or not without our having to make any cognitive inferences. In other words, affective reactions occur before evaluating artistry in consciously cognitive ways. ${ }^{8}$

What's most significant in this stage is that liking or disliking a performance means the same thing as evaluating it, even though no such evaluation of its formal techniques or artistic intentions occurs. Realists believe that theatre exists and functions solely for personal gratification, so the subjective criteria of personal preferences are the only necessary factors for "judging" artistic success or failure. As Deanna Kuhn explains, "there are no inaccurate renderings of [theatrical] events, nor any possibility of conflicting beliefs, because everyone perceives the same external reality." Because everyone holds the same perceptual advantage, there is no need to think critically about performances or to apply any objective criteria for evaluation purposes, as if to say: “It simply doesn't matter what other people think; all that matters is what $I$ think because only $I$ know what $I$ like and dislike." For instance, when selecting plays to produce for university seasons, realist decision-makers may reproduce the traditional canon by presuming that students need "mere exposure" to others' experiential preferences.

When instructors ask novice spectators to describe their emotional experiences and what they liked and disliked about performances, they inadvertently reinforce realist stances. As a consequence, when writing "critical" essays, realists may 
simply describe their aesthetic "tastes" by repeating their sensory and emotional experiences, copied or "imitated" from performances. To move realists beyond personally subjective claims, instructors might ask students to answer Johann Wolfgang von Goethe's basic questions of criticism when attending performances: 1) What is each artist (playwright, actors, director, designers) trying to do? 2) How well has each artist done it? and 3) Was the performance worth doing? ${ }^{10}$ Spectators' responses to these questions may further illuminate their epistemological stances and suggest particular methods for teaching performance criticism in introductory theatre courses.

Within critical essays, realists may jump ahead to the third question by presuming that a production was worth doing because artists already produced it and professors required them to attend a performance. Yet the first question requires students to infer or speculate upon respective artists' intentions before they can address the success/failure and worthiness of any theatrical event. If students claim that artists are merely trying to gratify their own and others' emotional pleasures, they are demonstrating stage one positions. Instead, they need to know and recognize that far more specific artistic intentions beyond personal aesthetic tastes initiate, drive, and "cause" aesthetic experiences. Cultural tastes merely reflect the by-products or aesthetic "effects" of artists' intended meanings that result from theatrical communication processes. Therefore, when students' essays move beyond statements of emotional experiences and aesthetic preferences to more specific inferences concerning artists' possible intentions, professors may know that students have advanced to other epistemological positions.

\section{Stage Position Two: Absolutists' Criteria of Realism and Moral Beauty}

When perceptual attentions shift from identifying preferences to studying the subject matter and formal content contained within a performance, spectators move into stage two positions by expecting artists to show them what life looks like. Perception remains the primary mode of inquiry, and evaluations now derive from comparing the external evidence of a performance with the realities of life itself - as they have experienced it. For instance, spectators often perceive similarities between themselves and actors' personalities, as expressed within dramatized situations, to sense what resonates with them personally. ${ }^{11}$ Yet only two criteria for making comparative judgments need apply-beauty and realism.

Values of aesthetic beauty and verisimilitude in relation to life's realities have been cultivated and normalized by the authorized expertise of theatre and mass media producers for generations. Decades of repeated exposure to "beautiful" depictions of "real life" have instilled in us an abiding attraction toward, a quiet contentedness in, and an unquestioned acceptance of what others favor most in the not-for-profit and corporate marketplaces. As Parsons further highlights, no one forces us to use these two interrelated factors when judging artworks, but we "accept 
society's criteria because they do so faithfully mirror our feelings. Their normative power comes from this fact, and was implied in stage one judgments too." 12 We now articulate these socially and economically sanctioned values in order to join with and belong to the wider aesthetic community by sharing our commonly held feelings about "good" and "truthful" performances.

Like neoclassical dictates of dramatic art, the prevailing assumption here is that performances are "supposed to" look like life's realities as readily apparent, fully transparent, and faithful representations of the phenomenal world. Rules of realism provide an easily accessible and organized structure that anyone can comprehend readily for evaluation purposes. Life occurs in a linear, causal chain of temporal and spatial events, so dramatic structures are expected to follow similar patterns of antecedent causes and consequential effects (e.g., the well-made play). Realistic representations capture the most prototypical and familiar style prevalent in television and film, especially when sharpened by computerized technologies. Familiar situations may be admired for their associated memories and nostalgic values (e.g., narrative dramas), while unfamiliar and fantastical situations may offer awe-inspiring insights into people, objects, and events we have not experienced (e.g., Cats). Knowing how difficult it must be for theatre artists to capture realistic details accurately in relation to life's models, spectators may privilege psychological realism over alternative acting styles (e.g., Hamletmachine) and spectacular special effects (e.g., Cirque du Soleil) over none at all.

Absolutists judge whether performances are either "good" or "bad" by comparing artists" "correct" or "incorrect" representations and whether they are "true to life and believable" or "fake and unbelievable" under the guise of "objective" criteria. Conceptualizations of beauty depend on how well artists manifest the publically known "essence" of depicted renditions and what may be considered "morally good" or socially acceptable dramatizations of life. Attractive works are more emotionally satisfying than "ugly" appearances and "offensive" content that may dismay, disgust, and disrupt aesthetic pleasures. If a performance doesn't dramatize one's experiential knowledge of reality and comes across as aversive, obscene, and repugnant, then it's absolutely "bad," "wrong," and "false." Aesthetics and morality are often conflated into one "goodness of fit" judgment, as many theatre artists know all too well from staging controversial productions (e.g., Corpus Christi).

Based on the presumption that representational objects, people, and scenic events are far more difficult to render live on stage than non-representational subjects on television and film, absolutists praise or criticize formal elements by pointing out artists' successful achievements (e.g., special effects that indicate fire) or sloppy "mistakes" (e.g., "fake" props). Either/or thinking patterns also apply to judgments concerning a play's subject matter. For instance, spectators may approve of Hamlet as a valued text, but dislike and reject any significant departures 
from its conventional staging (e.g., cross-gender casting). In reverse, they may admire highly realistic stage combat, but dislike Hamlet because they disapprove of fighting and violence. Similar dualistic judgments may apply to "beautiful or ugly" costumes that evoke positive or negative feelings, and scenic designs may be approved or disapproved based on their degrees of distortion from reality. When personal judgments between realism and beauty conflict, absolutists choose either one or the other criterion and ignore apparent contradictions by concluding that judgments about performances all depend on which of the two criteria one happens to choose or reverse.

When contending with highly abstract, non-representational productions (e.g., Waiting for Godot), absolutists can't detect potential "mistakes" in comparison to reality, so they may grow indignant or confused by non-linear and randomly organized dramatic structures, chaotic stage compositions, or verbal "nonsense" that any child might just as easily compose. They simply can't explain why artists would purposely dramatize something that no one can make sense of, other than just to be "different" and original by performing an absurdist play in order to gain attention and win fame. At this stage, "weird, stupid, or boring" performances may be attributed to artists" peculiar and inexplicable "tastes." For these reasons, postmodern performances are often blamed for failing to meet the all-abiding criterion of realism. When absolutist spectators can't make any sensible meaning from theatre, the fault lies entirely with artists and the content of their creations.

This commonly held attitude toward non-representational theatre arises from spectators' expectations regarding the utilitarian purposes art is presupposed to serve. When people expect theatre to show them life (only as they know it, mind you), then it follows that artists hold the sole responsibility for evoking aesthetic pleasure. And when artists believe they are solely responsible for ensuring spectators' pleasures, then it follows that their primary mission will be to please audiences by giving them what they desire most (e.g., popular culture, such as musical theatre). In other words, artists as well as spectators may orient themselves from stage two perspectives.

For dualistic absolutists, beauty and realism constitute implicit theories of theatre-implicit because spectators and artists rely unconsciously on both inductive and deductive reasoning, but without consciously coordinating and integrating these two basic modes of knowing. They study the particulars contained within the artistic evidence before them in order to arrive at general conclusions or "facts" about its objective (and objectionable) subject matter. Having deduced from the general world of reality what theatre "ought to" show and look like, they prescribe only the particular criteria of moral beauty and schematic realism, without considering alternative criteria outside the presumed credibility of authorized and publically sanctioned sources.

What's most significant at this stage is that spectators don't consider their own 
roles in the arts equation of aesthetic experience. While perceiving a performance, they implicitly ask themselves such questions as, "What is it?" and "What just happened?" to make sense of its actualized reality, and "Is it beautiful to me?" and "How do I feel about it?" based on immediate affective reactions. As Parsons points out, "the answers appear as perceptual facts, as if we have no part in constructing them. We do not acknowledge our contribution to the answers, or distinguish judgment as a distinct moment within experience." ${ }^{13}$ Critical thinking remains limited to making perceptual comparisons between the external features of performances and other phenomenal realities experienced in life. As Kuhn notes, "People can spend entire lifetimes within the protective wraps of either a preabsolutist stance in which assertions are equated with reality or, more commonly, the absolutist stance in which assertions can conflict but disagreements are resolvable by appeal to direct observation or authority." 14

Undergraduate and graduate students often place their faith and trust in professors' assertions without questioning their authorized credibility. Likewise, professors may uphold the theories and practices they've acquired from mentors and academic experts by justifying these sources as the most valid modes of inquiry to date, especially when fears of losing one's status in the academy inhibit conscious awareness of absolutist orientations. When professors defer to the majority of colleagues who will be most pleased by their choice of experts, the pivotal role of the decision maker may not necessarily figure into epistemological equations.

Regardless of personal epistemological stances, methods of questioning students during class discussions about performances may potentially spark absolutist (and realist) orientations unintentionally. For example, when asked to describe their individual experiences of a performance, students may dutifully obey by asserting their perceptual comparisons as "objective facts" under the guise of personal subjectivity. Knowing that their bodies lie outside and separate from the performance "objects" on stage, they may assume Kant's stance of "disinterestedness" by distancing themselves from any personally relevant conceptual metaphors that do not affect their lives directly. ${ }^{15}$ Making students aware of their unconsciously held sources of knowledge and their constrained criteria for understanding a theatrical event may move them to the next epistemological stage.

\section{Stage Position Three: Multiplists' Opinions about Artists' Expressed Intentions}

Spectators travel to stage three positions when they consciously recognize their own interpretative roles in generating aesthetic judgments as socially constructed transactions between themselves and artists' subjectivities. Expected purposes of theatre shift from identifying realistic beauty and moral norms to examining artists' expressed intentions (Goethe's first question) based on the evidence of their crafted abilities to achieve their own emotionally embodied experiences with genuine intensity. ${ }^{16}$ Spectators may speculate about artists' intentions and motives in order 
to explain why a performance was produced in the first place. Knowing one's own aesthetic sensibilities and privately held thoughts and feelings allows for a corresponding appreciation of artists' intentions, as spectators now consider their subjective opinions in relation to artists" "self-evident" reasons for deciding upon dramatic genres and theatrical styles. They know (consciously or unconsciously) that "aesthetics has always harbored an uneasy tension between the necessity of critical standards for judging art works and the fact that those standards rely upon the subjective responses of the individuals appreciating art, which are notoriously variable," as Carolyn Korsmeyer affirms. ${ }^{17}$ So at this stage, they interpret and judge the myriad forms of evidence contained in theatrical events by applying "objective" criteria as deduced and prescribed by theatre experts' socially established norms and critical theories.

However, at this relativist or multiplist stage, regardless of whether one agrees with particular artistic choices, value judgments have to do with respecting artists' individual rights of expressing their subjective experiences. Relativistic spectators believe that everyone is entitled to his or her own forms of self-expression and that no one person can judge whether artistic expressions are "right or wrong" or "true or false." Each person's preferential tastes and subjective opinions of artistic success or failure are equally "right" and "truthful" because individual critics also have the democratic right to express their multiple interpretations and naturally divergent opinions. Aesthetic judgments based on any one person's definitions of subjectively derived criteria are simply irrelevant, so again no critical thinking need be involved. As Mark Felton and Deanna Kuhn observe in regard to museums, simply exposing visitors to controversial exhibits (e.g., evolution) often fails to provoke multiplists and absolutists into making further inquiries and questioning how they know what they know about the arts, sciences, and history. "Whatever" may be heard as a common response when apathetic spectators don't really care whose opinion "wins or loses." In classroom discussions, silent students know that professors' opinions will ultimately win out anyway regardless of their own contrarian viewpoints.

Yet when personal judgments about a controversial performance differ wildly (e.g., Oleanna), people passionate about their interpretations may use critical thinking to dismantle others' claims - if they believe that engaging in a protracted debate is worth the cognitive effort with substantial educational payoffs. To win an argument with absolutists, multiplists may take them through their critical theories and procedural methods used to verify complex claims by relying upon other theatre critics' criteria. To support personal justifications, negotiated debates then revolve around "objective" examinations of artistic evidence discerned from a performance's formal elements and technical qualities (e.g., its structure, staging, acting, and scenography). For instance, by appealing to artists' and critics' constructs of stylistic classifications defined within historical and contemporary contexts, multiplists 
may argue on behalf of respective authors' mutually complex, ambiguous, and even paradoxical meanings that might render any given performance significant, valuable, and worthwhile to public audiences.

To these ends, relativists may select artistic evidence from a production that already fits with others' established theories. They may justify counter interpretations by noting alternative theories that substitute different evidence. In other words, multiplists' selections of theories, methods, and evidence are relative to whatever rules of inquiry have been instituted for scholarly debates in classrooms, at conferences, and across academic journals. Yet whatever mode of hermeneutic and phenomenological inquiry one chooses, any empirically derived evidence examined from socially constructed criteria constitutes elusive signs and slippery symbols of "proof"- burdens of which that appear (to me) to accentuate the circular conundrums of postmodern relativity, as Noël Carroll argues at length. ${ }^{19}$

In cases where absolutists refuse to accept and believe any evidence that does not compare favorably with their preferred theories (and their delusions of winning arguments), unsettled debates must inevitably come to a close for purposes of peaceful coexistence. In the end, people simply agree to disagree by voting democratically to decide whose opinions and self-justifications will win and lose. In regional and national cases where multiplists disagree on the artistic effectiveness and worthiness of performances, the winning view will depend on which set of critics - the theatre experts or the general public - holds the most persuasive power and cultural capital. When push comes to shove, public audiences' opinions and their consumer dollars may matter more than regional and national critics' awards for theatrical excellence in respective market economies. ${ }^{20}$

The pivotal problem that multiplists face is that they may not actually know artists' context-specific intentions embedded within playwrights' works and the planning, rehearsal, and technical circumstances that resulted in production choices. Even when critics speculate appropriately on artists' possible or probable meanings, artists themselves may report that they intended no such interpretations. For example, a highly respected scholar wrote an insightful essay concerning the compelling implications that arose from casting an African American actor in a postmodern performance- only to find out later from company members that this actor was cast simply because she was the most talented person available for the role. This critic's interpretations of the performance were not necessarily "false" or "misguided" but simply "inaccurate" in the sense that she did not have complete knowledge about all of the contexts surrounding the making of this production. While inquisitive interpretations often provide persuasive viewpoints on meaningful metaphors that apply to broader sociocultural contexts, another epistemological stance remains for fruitful consideration. 


\section{Stage Position Four: Reflective Critics' Cultural Responsibilities}

When we begin to doubt and question the very foundations upon which our entire history of personal epistemology has been fabricated, we move to a far more self-reflective and autonomous stance of individual agency that consciously recognizes our greater social and empathetic responsibilities to global cultures at large. Questioning the fabric of our epistemological tapestries allows us to push scholarly inquiry and argumentation forward to newly imagined territories of unsettled investigations. At this end-stage of aesthetic reasoning, we may revel in culturally shaped concepts more firmly revealed to us as symbolically laden metaphors created by our own embodied minds. ${ }^{21}$ When substantiating our plausible claims, we challenge existing theories for failing to account for available evidence, evaluate the explanatory power of our interpretations, consider the possible contingencies and potential consequences of our own and others' judgments, and humbly admit our human limitations and the ever-present risks of drawing erroneous conclusions.

Our criticisms of any theatrical event widen considerably as we consciously judge ourselves as both the subjects and objects of our systemized inquiries within academic institutions. By fully integrating both subjective and objective perspectives, we now question the very artistic criteria formulated by past and present critical and cultural theorists. As anthropologist Dorothy Washburn makes clear in her cross-cultural investigations of "aesthetic universals," "In the West, art critics dictate aesthetic criteria. But among people in societies such as the Hopi, everyone knows the principles and practices that lead to a perfect life and strives to live by them because the well-being of the community depends on everyone's participation" (her emphasis). ${ }^{22}$ Likewise, in her fancifully titled book, Homo Aestheticus, Ellen Dissanayake explains why we participate in our own and others' arts creations: to make our ordinary lives extraordinary and awe-inspiring. When we care deeply about our collective humanities, we symbolize and preserve our embodied experiences in the hope of shaping others', just as we have been changed by our most memorable aesthetic experiences. The fact that others may question and fail to value what we define as an "arts experience" for ourselves should not matter-if we can agree that, regardless of culture and contexts, human beings are far more alike than different. ${ }^{23}$

\section{Questioning Epistemological Positions}

From a critical evaluatist stance, how do we approach students' self-prescribed definitions and the culture-specific criteria they employ when judging the personal efficacy of their socially transacted theatre experiences? To what extent do we grant them the same agency as ourselves to argue, defend, and support their own self-reflective criticism in socially responsible classroom communities? Having 
wrestled with context-specific evidence, to what extent do we encourage them to question the very theories of performance criticism and time-tested practices of argumentation upon which we stand? If we expect any theatrical event to raise provocative questions and metaphoric truths about human lives, what "answers" may best satisfy the necessary and sufficient conditions of established rules of critical argumentation-beyond personal affirmations of what we already know and understand about theatre and life? I do not know.

I do know that these four epistemological perspectives represent gradational levels of education, as may have become apparent from my brief sketches. Cognitive developmental studies find that stage one captures preschoolers' stances, stage two characterizes most elementary students, and stage three personifies most high school and college students. Most striking is that the majority of adults continue to operate from absolutist and multiplist orientations, and very few reach the evaluatist level of epistemological understanding as skeptical critics. ${ }^{24}$ Instead, this end-state is most often characterized by those who hold doctoral degrees - university educators who initially promote and privilege critical argumentation in the first place! These self-constructed findings raise innumerable questions and troubling implications in regard to prejudicial charges against "intellectual elitism."

To address this quandary, educational psychologists recommend more explicit approaches to critical thinking and argumentation by confronting students with epistemic doubts about their embodied beliefs in order to create cognitive dissonance. If students were to question routinely authoritative theories and published evidence and constantly develop argumentation skills, then perhaps more might appreciate and engage in the dramatic thrill of negotiating conflicts - if they are willing to move beyond debilitating fears of losing faith in their current epistemological orientations. Likewise, we ourselves need the courage to question our own pedagogical assumptions and ideological beliefs, especially when critical theories and successful methods appear to be working to our evaluatists' satisfaction. ${ }^{25}$ While it is beyond the scope of this paper to suggest further methods for teaching performance criticism, knowing students' implicit and explicit epistemological orientations as theatre spectators holds promise for challenging and extending critical argumentation skills among undergraduate and graduate students.

Finally, from a more radical evaluatist perspective, I would like to raise just a few "unsettling" questions concerning my contrarian criticisms of postmodern theorizing. As Henry Bial writes, the field of performance studies "is for the people who like not knowing, who find the uncertainty of unmapped terrain exhilarating. . . The positive promise of performance studies - its potential to illuminate, instruct, and inspire-is enhanced, not diminished, by this ever-present uncertainty" (his emphasis). ${ }^{26}$ Now I admit that I still carry some unshakeable realist and absolutist tendencies, but I like knowing, with at least some ounce of certainty, potential answers to burning questions across variable-dependent contexts. My realist-driven 
mappings here obviously reproduce others' models (with a preference for quoting Kuhn's claims) to offer, what I hope, are some plausible "truths" about spectators' personal epistemologies during their engagements with performance criticism. And while I acknowledge the pitfalls of binary thinking habits, I still wonder why we have two-sided brains if not to allow us to reason inductively and deductively about dueling dualisms and dialectical debates so we may extract conditional balances between two contrasting extremes within and outside competing theories.

From multiplist and evaluatist stances, while I affirm that skeptical critics own the democratic right to express their rejections of cognitive psychology, what are the consequences of not integrating the epistemological and neuroscientific evidence of spectators' minds with idolized theories? As David Krasner and David Saltz point out,

the validity of performance theories ultimately rises or falls on arguments proffered by the theorists upon which the theory draws, rather than on the theorists' own argument. The shape of this type of argument is conditional: if we accept the arguments of [a preferred theorist], then certain ideas about theater or performance follow accordingly. One result of this approach to theory is that the sequence of theoretical discourse about theater and performance flows almost exclusively from elsewhere and into performance theory, and only occasionally does it flow out again to influence other disciplines. ${ }^{27}$

Admittedly, my proposed model of theatre epistemology flows from cognitive developmental psychology into performance criticism by offering another investigative and pedagogical means of understanding spectators' personal theories of knowledge and knowing performances. In order to reverse this flow back to cognitive disciplines, theatre researchers need to conduct reception studies with present-day spectators by gathering and analyzing their perceptions, interpretations, and criticisms of various theatrical events. ${ }^{28}$ By documenting, sharing, and debating the evidence of spectators' epistemological positions and weighing this accumulated evidence against a myriad number of existing theories, we may explain why only $9 \%$ of US spectators (or 21 million people) attend live theatre annually and only $4 \%$ read plays for leisure. ${ }^{29}$ While invariably complex and interdependent reasons most likely account for these low and still decreasing theatre attendance figures (e.g., competing mass media technologies), the evidence of these national conditions also suggests consequential mismatches between theatre producers' artistic intentions and spectators' epistemological expectations.

Yet such studies will not happen unless and until more self-reflective critics in stage four positions question the consequential values of current performance 
theories and release their understandable fears and anxieties over cognitive theories and empirical methods of qualitative research..$^{30}$ As Howard Gardner surmises, changing people's minds and their epistemological orientations requires reasoned research that will resonate emotionally against their resistant beliefs concerning explanatory representations of real spectators with compelling rewards. ${ }^{31}$ While such a research agenda obviously necessitates a retooling of training in cognitive science, skeptical critics still need to doubt and question ongoing integrations of multifarious social-cognitive and affective theories with a growing body of neurological evidence. For instance, if our mirror neurons enable empathetic tendencies, not only for human survival, but for the survival of live theatre, what would happen to performance criticism if critical thinking strategies were displaced as the end-state of personal epistemology in favor of more emotionally resonant and less cognitively resistant appeals of persuasion? How might we characterize a potential "fifth" stage of theatre epistemology that captures peaceful reconciliations and theoretical coordinations with cognitive and neuroscientific disciplines beyond argumentative debates contested solely within and among the circles of theatre and performance studies? I look forward to exploring further epistemological avenues of theatre spectatorship, especially those migrations that move us beyond the mapped terrains of performance practices, dramatic literature, and theatre historiography toward hopeful (and utopic) reconciliations with personal theories of mind.

\section{Notes}

1. Anais Nin, Seduction of the Minotaur (Athens, OH: Swallow Press, 1961) 124.

2. For details, see Barbara K. Hofer and Paul R. Pintrich, "The Development of Epistemological Theories: Beliefs about Knowledge and Knowing and Their Relation to Learning," Review of Educational Research 67.1 (Spring 1997): 88-140. In this review, they integrate the following major epistemological models: W. G. Perry, Forms of Intellectual and Ethical Development in the College Years: A Scheme (New York: Holt, Rinehart and Winston, 1970); Mary Field Belenky, Blythe McVicker Clinchy, Nancy Rule Goldberger, and Jill Mattuck Tarule, Women's Ways of Knowing: The Development of Self, Voice, and Mind (New York: Basic Books, 1986); Marcia B. Baxter Magolda, Knowing and Reasoning in College: Gender-Related Patterns in Students' Intellectual Development (San Francisco: Jossey Bass, 1992); Patricia M. King and Karen Strohm Kitchener, Developing Reflective Judgment: Understanding and Promoting Intellectual Growth and Critical Thinking in Adolescents and Adults (San Francisco: Jossey Bass, 1994); Deanna Kuhn, The Skills of Argument (New York: Cambridge U P, 1991); and Marlene Schommer, "Synthesizing Epistemological Belief Research: Tentative Understandings and Provocative Confusions," Educational Psychology Review 6.4 (1994): 293-319. For subsequent updates on these models, see the special issue of Educational Psychologist 39.1 (2004), especially Lisa D. Bendixen and Deanna C. Rule, "An Integrative Approach to Personal Epistemology: A Guiding Model," 69-80. For the purposes of this paper, I employ Deanna Kuhn's developmental framework of epistemological understanding from her book, Education for Thinking (Cambridge, MA: Harvard U P, 2005) 30-33.

3. Michael J. Parsons, How We Understand Art: A Cognitive Developmental Account of Aesthetic Experience (New York: Cambridge U P, 1987). For comparative purposes, see Abigail Housen, "Eye of the Beholder: Research, Theory and Practice" (New York: Visual Understanding in Education, 2001) < www.vue.org $>$; and, Annelies van Meel-Jansen, "The Magical Number Five in Art Appreciation," Empirical Studies of the Arts 24.1 (2006): 107-118.

4. Reception studies have been conducted in Europe since the 1980s, yet none have focused 
on exploring spectators' personal epistemologies, per se. For details, see Jacqueline Martin and Willmar Sauter, Understanding Theatre: Performance Analysis in Theory and Practice (Stockholm: Almqvist and Wiksell, 1995) 26-34; Willmar Sauter, The Theatrical Event: Dynamics of Performance and Reception (Iowa City: U of Iowa P, 2000); and, Theatrical Events: Borders, Dynamics, Frames, eds. Vicky Ann Cremona, Peter Eversmann, Hans van Maanen, Willmar Sauter, and John Tulloch (Amsterdam: Rodopi, 2004).

5. Patricia M. King and Karen Strohm Kitchener offer a particularly useful set of definitions that include transitions between their stages in "Reflective Judgment: Theory and Research on the Development of Epistemic Assumptions Through Adulthood," Educational Psychologist 39.1 (2004): 7-8.

6. For further details, see Deanna Kuhn, "A Developmental Model of Critical Thinking," Educational Researcher 28.2 (1999): 16-26.

7. For example, see Christopher Thaiss and Rick Davis, Writing About Theatre (Boston: Allyn and Bacon, 1999).

8. Robert B. Zajonc, "Attitudinal Effects of Mere Exposure," Journal of Personality and Social Psychology Monographs 9.2 (1968) pt.2: 1-27, and "Feeling and Thinking: Preferences Need No Inferences," American Psychologist 35.2 (Feb. 1980): 151-175.

9. Kuhn, Education for Thinking, 31.

10. Johann Wolfgang von Goethe, "On Criticism (1821-24)." Goethe's Literary Essays: A Selection in English, arr. J. E. Spingarn (1921; New York: Frederick Ungar Publishing, 1964) 140.

11. European reception studies find that spectators respond most to actors' personalities (in Martin and Sauter, Understanding Theatre, 34). For debates on spectators' perceived relationships with actors/ characters, see Jonathan Cohen, "Audience Identification with Media Characters, in Psychology of Entertainment, ed. Jennings Bryant and Peter Vorderer (Mahwah, NJ: Lawrence Erlbaum, 2006) 183-197.

12. Parsons, 125.

13. Parsons, 122.

14. Kuhn, "A Developmental Model of Critical Thinking," 22.

15. See Donald W. Crawford, "Kant." The Routledge Companion to Aesthetics, ed. Berys Gaut and Dominic McIver Lopes (New York: Routledge, 2001) 53.

16. Note that I have merged Parsons' third and fourth stages of artistic expression and media styles into one third stance of personal epistemology here.

17. Carolyn Korsmeyer, "Taste," The Routledge Companion to Aesthetics, ed. Berys Gaut and Dominic McIver Lopes (NewYork: Routledge, 2001) 193.

18. Mark K. Felton and Deanna Kuhn, “'How Do I Know?' The Epistemological Roots of Critical Thinking," Journal of Museum Education 32.2 (Summer 2007): 101-123.

19. Noël Carroll, "Prospects for Film Theory: A Personal Assessment." Post-Theory: Reconstructing Film Studies. Ed. David Bordwell and Noël Carroll (Madison: U of Wisconsin P, 1996) 37-68.

20. For example, see Dean Keith Simonton, "Cinematic Creativity and Aesthetics: Empirical Analyses of Movie Awards," New Directions in Aesthetics, Creativity and the Arts. Ed. Paul Locher, Colin Martindale, and Leonid Dorfman (Amityville, NY: Baywood, 2006) 123-136.

21. For example, see George Lakoff and Mark Johnson, Philosophy in the Flesh: The Embodied Mind and Its Challenge to Western Thought (New York: Basic Books, 1999). See also Bruce McConachie's applications of these and other cognitive theories of spectatorship in Engaging Audiences: A Cognitive Approach to Spectating in the Theatre (New York: Palgrave Macmillan, 2008).

22. Dorothy Washburn, "Aesthetic Universals in Cultural Perception and Practice." New Directions in Aesthetics, Creativity and the Arts. Ed. Paul Locher, Colin Martindale, and Leonid Dorfman (Amityville, NY: Baywood, 2006) 68.

23. Ellen Dissanayake, Homo Aestheticus: Where Art Comes From and Why (New York: Free Press, 1992).

24. For example, in the case of jurors, see Deanna Kuhn and Michael Winestock, "What Is Epistemological Thinking and Why Does It Matter?" Personal Epistemology: The Psychology of Beliefs about Knowledge and Knowing. Ed. Barbara K. Hofer and Paul R. Pintrich (Mahwah, NJ: Lawrence Erlbaum Associates, 2002) 121-144.

25. Bendixen and Rule, "An Integrative Approach to Personal Epistemology," 69-80; and, Kuhn, Education for Thinking, 132-173. For ideas regarding theatre history courses, see Lendol Calder, 
"Uncoverage: Toward a Signature Pedagogy for the History Survey," Journal of American History (March 2006): 1358-1370. 2004) 1 .

26. Henry Bial, ed., introduction to The Performance Studies Reader (New York: Routledge,

27. David Krasner and David Z. Saltz, introduction, Staging Philosophy: Intersections of Theater, Performance, and Philosophy. Ed. David Krasner and David Z. Saltz (Ann Arbor, MI: U of Michigan P, 2006) 8.

28. Sauter offers useful suggestions for conducting theatre talks with spectators in The Theatrical Event, 174-186.

29. National Endowment for the Arts, All America's a Stage: Growth and Challenges in Nonprofit Theatre (Washington, D.C.: National Endowment for the Arts, December, 2008); and, National Endowment for the Arts, To Read or Not to Read: A Question of National Consequence (Washington, D.C.: National Endowment for the Arts, November, 2007).

30. Rhonda Blair, "(Refuting) Arguments for the End of Theatre: Possible Implications of Cognitive Neuroscience for Performance," Journal of Dramatic Theory and Criticism 21.2 (Spring 2007): 125-132.

31. Howard Gardner, Changing Minds: The Art and Science of Changing Our Own and Other People's Minds (Boston: Harvard Business School P, 2006) 15-19, 161-163. 
